\title{
Art and Techniques for Oral Presentation in Distance Education
}

\author{
A. Q. M. B AZLUR RASHID* \\ School of Agriculture and Rural Development, Bangladesh Open University, Gazipur, Bangladesh
}

Received 19 June 2006; received in revised form 22 June 2006; accepted 22 June 2006

\begin{abstract}
Human being is only the unique verbal monster in the nature having worldwide communicative power capable of conveying his thought or deliberation and/ or message/information outside his head to others through different ways among which the vocabulary speech is significantly more important and effective. The instructional approach through multi-mediated method of distance education requires persuasible and emanating resourceful speaker with vocabulary and other necessary art and techniques. Relevant qualifications of the speaker along with some important points of consideration such as determination to succeed, control over nervousness, contemporary knowledge, vocabulary efficiency, choice of words and other techniques for opening presenting and closing a speech etc. have been described. Various art and manner including smiling face with emanating attitude, language and style etc. along with avoidable distracting habits of the presenter have also been elucidated in detail.
\end{abstract}

Key words: Art and technique, oral presentation, distance education.

\section{INTRODUCTION}

With the astounding progress of modern scientific expositions, especially in the field of information and communication technologies (ICTs) the whole universe has become in the strategic blow of human beings. Under this globalized context much changes have been brought enhancing and expediting into the day to day human activities. Likewise, the yesterday's convention of educational system cannot meet today's requirements in this rapidly changing world. Hence, the modern education system as open and distance learning has already been proved to be a potential alternative to the conventional system of education as per growing need and relevance in today's context, and has become a hot cake in the recent world.

Distance education is simply defined as the multi-media approached correspondence through which the education is imparted to the learners from a distance. One of the most visible attributes of distance education is its emphasis on the use of technology to accomplish its goal. It can be seen as a set of instructional methods based largely on mediated communication capable of extending the influence of education beyond the formal institutional setting for the purpose of benefiting the learners through appropriate guidance and support (Manjulika and Reddy, 1998).

Human beings are only the unique verbal monster in the nature having the power of world-wide communication to convey his thought or deliberation and/or messages/information outside his head

\footnotetext{
* Corresponding author: Professor \& Dean, SARD, BOU, Gazipur-1705. E-mail: aqmbr@yahoo.com

(C) 2006, School of Agriculture and Rural Development, Bangladesh Open University. All rights reserved
} 
to others through different ways among which the vocabulary speech is significantly more important and effective (Bazlur Rashid, 2006). Although the vocabulary speech is essentially important in the conventional face to face education system in the schools, colleges and universities, it is almost equally important in the mediated instructional and communicative media and methods such as Television, Teleconferencing, Video cassette etc. Actually the effective oral presentation depends on the ability of the speaker to communicate with the learners in education techniques for life long learning (Collins, 2004). This paper focuses on how to present a speech effectively to the learners and viewers through the distance media such as television, teleconferencing, video cassette etc.

\section{REQUIREMENTS AND TECHNIQUES}

Oral presentation is an instructional approach practically using tongue and gesticulations to the learners and viewers. This is nothing but the expression skill of a speaker on the concerned topic/subject with effective and captivating artistic manner. The successful presentation needs some important points of consideration.

\section{Qualification of speaker}

The effective way of presentation of a speech is equally important as the quality of the contents of the speech. It is important that the presentation should be purposeful and directed at facilitating learner's achievements of the concerned objectives. The successful presentation may be emphasized with some necessary art and techniques to be applied by the speaker. The following points may be considered before going to present or deliver a speech for fruitful presentation.

i) Determination to succeed : While the speaker goes to the dias he/she should possess the strong determination that he/she will have the successful presentation and should forget the psychological weakness if any. The most useful method to this end is to make the learners and viewers active partners of the speech through brain storming questioning, directed listening etc.

ii) Control over the 'butterfly' inside : The expression ability of a speaker is related to his internal 'butterfly' of heart-beat which may reflect to the compatibility of persuasibility and emanation on the topic. This butter flying condition is nothing but the assumed weakness of the speaker on the topic. All other speakers as well as the audience alike may have the same weakness. If it is considered in mind it may reflect complicating to the vocabulary expression. Many speakers, even the famous executives sometimes become fearful in presenting to a large group. They suffer from a stage fright, a negatively used term for excitement which should be channelled into positive enthusiasm. To avoid the stage fright as well as the faster and louder heart beat it may be considered that the speaker is "one of the best experts and great authorities on the topic". Unless a speaker recognizes and accepts this fact, he can not make himself as a good speaker, especially in case of distance media-based instructional education. The learners and viewers in such cases loose their imbibing interest as well. The most useful method of controlling nervousness is to visualize success. When showing images, it is important to orient the audience with an adequate description, point out the relevant findings and allow enough time for the viewers and audiences to assimilate the information. Such interacting visualized presentation helps in controlling stage fright of the speaker as well as active participation of the learners for effective lecture specially in distance mode.

iii) Sufficient contemporary knowledge on the topic : The speaker must be well prepared with sufficient treasury of contemporary knowledge on the topic to be presented. The relevant information along with references (if any) on the topic are one of the main capital/investment qualifying the speaker to be resourceful, persuasible and emanative. This is very important especially incase of video teleconferencing etc. The quality and effective presentation may be facilitated with the appropriate use of cursor, laser pointer etc.

iv) Vocabulary efficiency with correct pronunciation : Efficient vocabulary capability with correct pronunciation is one of the main factors to present the speech effectively to the learners and viewers. As because the oral presentation is actually a practical skill and it is important that the speaker should have well practice personally prior to come to the delivery 
stage/studio to develop self awareness and self confidence. Because, there is no alternative of practicing particularly in case of physical approach of effective presentation in the media based technology. A good rehearsal is an important aspect of fruitful presentation. It allows the speaker an opportunity to gauge how long the talk will take, plan for pauses at opportune times during the presentation, and be effectively familiar with the power point focal points or slides etc. It allows the speaker to know where the key segments of the speech are so as to move easily with the cursor or pointer to answer the probable questions of the learners, rather than scrolling through the materials.

v) Choice of words : It is important that the speaker should always be careful in his choice of selecting words as like as the painter in the choice of shades, shadows and lights. Any controversy and/or culturally sensitive words should always be avoided not to create psychological inconvenience to the learners and the viewers.

\section{How to open and present a speech}

When a speaker steps to the dias he/she should have a break up at a moment in his/her brain on the important points to be accomplished within the stipulated period of time. Otherwise he/she will not be able to complete the speech fruitfully.

i) A good address to be made to the learners/viewers and good wishes to everybody.

ii) The topic to be presented should be mentioned in brief or repeated with a good start with clear objectives.

iii) The main exposure should be followed by the attractive relevant visual aids, inserts of photographs, tables/charts, figures etc. which may dramatically enhance the quality of the presentation. Such presentation enables the learners to be effective partner of the speaker as well. Otherwise the presentation of mere monotone lecture may suffer.

iv) The unfamiliar terms should be translated and made easier into comprehensible and understandable form.

v) The speech should not be crowded with too much detail. Because, the speaker may loose the thread of his/her ideas in a sea of figures.

vi) Avoidance of emotion: During presentation the speaker may create emotion in the sentiment of the audience/listener but he himself must not be emotional.

vii) Reading notes : A good presentation seldom needs any note. So much frequently reading notes on the table/dias may convince the learners/viewers that the presenter is unprepared which is not desirable for the successful presenters. Off course, many people carry notes for insurance. As Winston Churchill said when he was asked why he carried notes but seldom used them, "I carry fire insurance, but I don't expect my house to burn down" (Brody, 2003).

\section{Timing}

The time budgeted for the schedule is one of the most important criteria to be considered in fruitful presentation. Because the learners and audiences usually have their expectations as to when the presentation will start and end, and the speaker/presenter who strays out the stipulated timing risks irritating the learners. A good strategy is to plan, prepare, and practice for $75 \%$ of the allotted time. It is better to end a little early than late. Ending late reflects poor planning. If there is to be audience involvement, it is appropriate to plan on using $50 \%$ of the time for the planned presentation and $25 \%$ for interactive facilitated sessions (Anonymous, 2004).

\section{Art and Manner}

Art and manner, the most important phenomenon for the successful presentation deserve the quality of the pertinent speaker. The following points may be followed during the speech for successful presentation.

i) Smiling face with emanating attitude: Speaker should be in captivating artistic manner with smiling face and attitude. It is first necessary to draw imbibing attention of the learners and viewers for motivation. This may be accomplished through appropriate use of humorous attitude, anecdotes, quotation etc. Simultaneously, attention should be given to the posture, 
gesticulation (body movement), eye contact, voice etc. as how the speaker appears to the learners and viewers will have an impact on their reaction to what is going to be presented.

Because a presenter never gets a second chance to make a first impression. While Mc Leish (1976) opined that the first impressions were lasting, and student awareness and receptiveness were highest during the first five minutes of a lecture.

It is important that how a presenter appears to the learners and viewers that will have an impact on their reaction to what is going to be presented. Gesticulation is actually the visual reinforcement of the words and ideas to be communicated or disseminated to the learners to this end. Hand, arm, head movement etc. may enhance the presentation or even detract from it. Nodding the head and smiling may be very useful to emphasize what is being said, although it is not always easy to smile and speak at the same time. But still it is important to smile during the presentation if congruent with the message/information being spoke.

ii) Viewer in air: The speaker should not leave the listeners/audiences/viewers in the air. They should be the rightful and active partner of the speaker. Sometimes questions and attractive symbolic gesticulations/guesture may be accompanied with the speech.

iii) Language and style:Language and style should be used as liked by majority of the people.

\section{Distracting habits to be avoided}

i) Incompatible dress and undressed mien.

ii) Repetition of the same word "You know", "See what I mean?" "Again and again" etc.

iii) Standing like a statue.

iv) Moving like an enraged elephant on the dias / recording place.

v) Playing with keys, pen or anything else.

vi) Putting hands in the pockets which often results in jingling of change.

vii) Looking out of the windows / out of focus.

viii) Barring the view of the audience to the blackboard.

ix) Writing in an unclean board.

x) Cleaning the board with hand (Use a duster!).

xi) Use of stick / laser pointer not necessary etc.

\section{How to close presentation?}

The closing conclusion should highlight the main points of the topic summarizing the speech to be ended smoothly. It should not make a long conclusion which may kill the speech.

\section{CONCLUSION}

Practicing art and techniques for oral presentation in distance education is undoubtedly an indispensable phenomenon especially applicable for the BOU educators. Due importance should be emphasized by the concerned speaker on this issue for successful communicative ways with learners and viewers at a distant places.

\section{LITERATURE CITED}

Anonymous. 2004. Art and Techniques for Lifelong Learnings. Radio Graphics 24, 1185-1192.

Bazlur Rashid, A. Q. M. 2006. Art and Techniques for Oral Presentation in Distance Education. Paper presented in the Training on Capacity Building for Open and Distance Learning at BOU. 12-19 March, 2006.

Brody, M. 2003. Highly effective presentation techniques. <http:// www.powerpointes.com/showarticle.asp>

Collins, J. 2004. Education techniques for lifelong learning. Radio Graphics 24, 1185-1192.

Manjulika, S. and Reddy, V. V. 1998. Emerging Technologies and their Impact on Distance Education. In "Distance Education in India; A Model for Developing Countries". Associated Business Corporation and Vikas Publishing House Pvt. Ltd., New Delhi. p. 229.

Mc Leish, J. 1976. The lecture method. In "The psychology of teaching methods" (N. L. Cage, Ed.), Chicago, III. University of Chicago Press. 